\title{
Interfirm Trust between Emerging Markets: Chinese Firms in Africa: An Abstract
}

\author{
Esi A. Elliot, Zhen Zhu, and Fei-Ling Wang
}

\begin{abstract}
The rapid global expansion of marketers from one emerging market to another such as countries in Africa, Latin America, Central Asia, and the Middle East is dramatically changing the landscape of international business relationships. A leading example is Chinese firms in African countries. The element of trust is highlighted in such emerging market relationships that involve large investments from multiple constituents with diverging and sometimes conflicting objectives. Our study provides a broader, more encompassing macromarketing framework by investigating interfirm trust between two emerging markets from an institutional perspective. Our study develops the interfirm trust concept in the context of Chinese businesses in Africa on the bases of extant literature, field interviews, and observations focused mainly on three African countries (Ghana, Kenya, and South Africa). Drawing from trust theory and institutional theory, our study focuses on how crosslevel factors influence or are influenced by the meso-level inter-firm trust between emerging markets and reveals three dimensions for the inter-firm trust concept and both trustor and trustee factors influence the perception of Chinese businesses in Africa. Macromarketing and practical implications for building and managing interfirm trust at a multilevel between emerging markets are also discussed.
\end{abstract}

References Available Upon Request

Esi A. Elliot and Zhen Zhu are contributed equally in this chapter

\author{
E. A. Elliot ( $ه)$ \\ Suffolk University, Boston, MA, USA \\ e-mail: eaelliot@suffolk.edu \\ Z. Zhu \\ e-mail: zzhu@ suffolk.edu \\ F.-L. Wang \\ Georgia Institute of Technology, Atlanta, GA, USA \\ e-mail: fw@gatech.edu
}

